\title{
DISCURSO PROFERIDO PELA SRA. MARIA DA GRAÇA SIMÓES CÔRTE IMPERIAL, PRESIDENTE DA ABEn, NA SESSÃO DE INSTALAÇÃO DO XXVIII CONGRESSO BRASILEIRO DE ENFERMAGEM E I CONGRESSO SUL-AMERICANO DO CICIAMS. EM 12/8/1976
}

Ao abrir o XXVIII Congresso Brasileiro de Enfermagem e o I Congresso SulAmericano do CICIAMS, na Cidade do Rio de Janeiro, elevamos o pensamento a Deus que permitiu à nossa Associação crescer e desenvolver-se, mantendo o espírito coeso e integrativo dos seus assc ciados, o que caracteriza a atitude matura e consciente de um membro da equipe de enfermagem. Jubilamo-nos em Cristo, que preside do Corcovado a vida desta Cidade, em aqui estarmos para realizar este Congresso.

Aquí nasceu, em 1925, a enfermagem de alto padrão técnico e científico, quando a Escola Ana Neri do Departamento Nacional de Saúde Pública do Brasil, diplomou a 1.a turma de Enfermeiras.

Eram 15 jovens a quem no período do Curso, sob os sólidos alicerces de um espírito elevado e puro como o de Miss Ciara Louise Kieninger, $1 .^{\mathrm{a}}$ Diretora da Escola, foram legados sábios conhecimentos para formação profissional; aprenderam a amar a profissão; assimilaram o grande ensinamento de seu exemplo, o espírito da verdadeira enfermeira, transmitindo-o às geraçōes que se seguiram através dos tempos. Mostraram ao Brasil uma profissão nobre que se tornou conhecida mesmo fora dos limites das Instituiçōes de saúde, que é compreendida e procurada pelo público para maior segurança na atenção à sua saúde. Sua atuação esten- de-se à participação das atividades de planejamento de programas sanitários, a nível local, regional e nacional; às rostruturaçōes dos Serviços de Saúde ou sua expansāo que vêem a Enfermeira como integrante imprescindível, de alta prioridade na equipe. Colhemos portanto hoje, os frutos dos esforços das que nos antecederam.

Estamos comemorando o Jubileu de Ouro da Associação Brasileira de Enfermagem. A vida associativa das Enfermeiras vem desde 1926, quando um grupo de ex-alunas e docentes da Escola Ana Neri, motivado pelo dinamismo de suas dirigentes e em especial de Miss Ethel Parsons, Superintendente do Serviço de Enfermeiras do Departamento Nacional de Saúde Pública que incentivava as Enfermeiras a pertencerem à Associação de classe, demonstrou preocupação em incluir o Brasil como membro filiado do ICN (Conselho Internacional de Enfermeiras) para poder participar em Montreal (1929) do Congresso Quadrienal do Conselho. A continuidade daquele incentivo foi assegurada pelas dirigentes que sucederam Miss Kieninger. Hoje, entre nós está presente uma dessas Mestras que, deixando o seu país em 1934, com as brasileiras veio construir uma nova profissão - a Enfermagem. O calor de nosso respeito à Miss Bertha Lucille Pullen 3.a Diretora da Escola de Enfermagem Ana Neri. 
Coube à ilustre Enfermeira Edith de Magalhães Fraenkel, diplomada pela Escola de Enfermagem de Filadelfia, iniciar a organização da Associação com entusiasmo, idealismo e convicta de que "para uma profissão progredir é necessário que possua uma Associação de Classe e uma Revista". Assim, a 12 de agosto de 1926 é criada a Associaçāo Nacional de Enfermeiras Diplomadas, hoje Associação Brasileira de Enfermagem. Ao rememorar esse importante acontecimento. desejamos destacar a figura de D. Edith de Magalhães Fraenkel e suas colegas, que iniciaram com ela, a 6 de agosto de 1926, os trabalhos de organização. São as sócias fundadoras: Cecy Clausen, Heloisa Maria Carvalho Veloso, Izaura Barboza Lima, Isolina Lóssio, Judith Arêas, Odete Seabra, Remidia Bandeira de Souza Gayoso, Alice de Araújo, Noélia de Almeida Costa e Maria Josephina Brito Rocha.

Após o periodo de organização dessa Diretoria provisória, que estudou os Estatutos da Associação, D. Edith Fraenkel, como $1 .^{\mathrm{a}}$ Presidente eleita, teve uma atuação destacada na vida associativa. Dentre suas inúmeras realizações pelo fato de ter exercido a presidência da ABEn em vários periodos (1926 a 1950), as mais importantes foram: representar o Brasil como delegada oficial no Congresso Quadrienal do ICN, tomando parte ativa nos debates e com brilhantismo defendeu a Associação como membro filiado; participar da criação da Revista (1932) - "Anais de Enfermagem", posteriormente Revista Brasileira de Enfermagem; dar início aos Congressos Brasileiros de Enfermagem. O primeiro Congresso em 1947, realizado na Cidade de São Paulo, acontecimento brilhante que reuniu altas autoridades brasileiras e norte-americanas. Dentre as resoluções aprovadas, a primeira e a mais importante foi a que solicitava dos órgãos competentes, a criação do Conselho Federal de Enfermagem, concretizado 26 anos depois pela Lei n. ${ }^{\circ} 5.905$ de 12 de julho de 1973.
Em 1949, como Presidente da ABEn, representou o País nas reuniōes do ICN na Suécia, onde sugeriu o nome do Brasil como Sede do $\mathbf{X}$ Congresso Internacional, o que se efetivou em Petrópolis Rio de Janeiro, em 1953, sob a Presidência de Dra. Glete de Alcântara, Presidente da Associação Brasileira de Enfermagem na época.

A menção do nome de Dra. Glete de Alcântara, naquela participaçāo, reaviva de imediato em nossas mentes e nossos corações a memória daquela que foi nossa última Presidente, desaparecendo do nosso convivio em meio de seu mandato. Líder inconteste no seio desta Associação, deixou para nós a lição de uma vida dedicada à sua profissão e à sua Associação de Classe. Se aqui estivesse dar-nosia o enriquecimento do seu saber, a elevada qualidade de suas experiências profissionais sempre pautadas por uma abordagem ético-profissional da mais pura formulação filosófica, social e humana.

Tem sido diretriz de várias Diretorias, o fortalecimento da Associação, o despertar nas enfermeiras da idéia de participação indispensável para o estabelecimento de uma política de trabalho eficiente. As atividades de caráter cultutural e científico estão definidas em seus Estatutos, visando o desenvolvimento da enfermagem em todos os ramos, seja no ensino e formação do pessoal de enfermagem, na prestação de serviços cuja qualidade assegure ao usuário condiçōes de segurança para sua vida, seja pesquisando novas fórmulas para a solução dos problemas de enfermagem sempre firmada nos mais altos padrões da ética da enfermagem.

Através de suas comissões, nesses anos de existência, tem incentivado as Seções a desenvolverem programas de atualização e de educação em serviço para 0 pessoal de enfermagem; documentou a situação de escolas e cursos de enfermagem ao fazer o "Levantamento de Recursos e Necessidades de Enfermagem" no País; estudou os problemas relacionados com o ensino nos diferentes níveis de 
enfermagem, oferecendo subsídios ao Ministério da Educaçāo e Cultura e ao Conselho Federal de Educação para a seleção e preparo de alunos e capacitação Docente. Baixou normas para elaboração de Regimentos de Enfermagem; estabeleceu critérios para a seleção dos campos de prática, no que diz respeito à legislação do ensino e do exercício profissonal. Conquistou para a classe os documentos legais do ensino e do exercício, batalhando para mantê-los atualizados. Sempre atenta à tramitaçāo dos projetos de interesse da enfermagem nas Casas do Congresso, assumiu continuamente a liderança da Classe.

Rejubilando-nos com a existência deste belo espírito de"progresso da Associaçāo Brasileira de Enfermagem, esta abençoada vontade de servir de seus associados é que iniciamos os nossos trabalhos. Saudamos com simpatia e afeto todos os Congressistas que vieram dos mais distantes pontos do País e do estrangeiro, trazendo o seu melhor propósito de trabalho e de realização.

Dentre os temas a serem abordados e discutidos durante o Congresso destacamse pelo alto sentido educativo, religioso e patriótico, assuntos de grande importância para a Classe: o primeiro refere-se à "Formaçāo filosófica e religiosa da Enfermeira"; o segundo, "Projeçāo da ABEn na comunidade brasileira".

E para reavivar em nós o sentido cristāo de servir que ora nos reunimos; o serviço no sentido cristão requer o desejo de enriquecer e ampliar a gama de nossos deveres profissionais. Conscientes das atividades profissionais e religiosas das enfermeiras para torná-las mais capazes de prestarem serviços com a maior perfeiçāo técnica e com a maior doaçāo de nós mesmas a Deus e ao próximo; conscientes da necessidade de atuar mais ainda no processo de desenvolvimento do País, a Associaçāo Brasileira de Enferma- gem se manifesta sempre pronta a cooperar com o Governo nas esferas: Federal, Estadual e Municipal, nos trabalhos de construção de um sistema docenteassistencial aperfeiçoado e mais humano.

$\mathrm{Na}$ qualidade de representante da enfermagem brasileira quero expressar os especiais agradecimentos às autoridades presentes ou representadas e a alegria de ter conosco as Delegaçōes de quase todos os Países Sul-Americanos que acorreram ao nosso chamado para compartilhar dos nossos trabalhos e oferecer-nos o fruto de suas experiências. Bem-vindas sejam a este agradável convívio no qual se há de dimensionar o fecundo labor de dar e receber. A mestra das mestras, a mestra das enfermeiras brasileiras, a ilustre Enfermeira Miss Bertha Lucille Pullen que engrandece este Conclave com sua honrosa presença dando-nos o atestado de fé nos destinos da enfermagem brasileira, nossa reverente gratidāo. Aos que aqui vieram para prestigiar esta solenidade, 0 caloroso reconhecimento de toda uma classe voltada para o bem comum. Aos que prosseguirem colaborando para o êxito da realização deste Congresso os antecipados agradecimentos da Comissão Executiva.

Declarando, pois, abertos o XXVIII Congresso Brasileiro de Enfermagem e o I Congresso Sul-Americano do CICIAMS, é nosso dever lembrar o compromisso de jamais fraquejarmos na peleja de engrandecimento da profissāo que abraçamos, estreitamente ligada ao bem-estar do próximo. Que nunca nos falte o entusiasmo indispensável para prosseguirmos, por ele, por nós, e pelo Brasil.

A fé é uma graça que, como todas as outras, recebemos gratuitamente de Deus. Somos, contudo, responsáveis pela conservação da mesma e por alimentá-la adequadamente para que se fortaleça e em nós aumente, ocupando o centro de irradiação da nossa vida espiritual. 